\title{
Tubercular Tenosynovitis of Extensor Tendon of Wrist Mimicking a Ganglion
}

\section{Kapil Rampal *1, Devendra K Prajapati ${ }^{1}$, Meghna Sharma ${ }^{2}$, Raj Kumar Indoliya ${ }^{1}$.}

${ }^{* 1}$ Deen Dayal Upadhya Hospital, Hari Nagar, New Delhi, India.

${ }^{2}$ CHC, Kasel, Tarn Taran, Punjab, India.

\section{ABSTRACT}

Tuberculosis of tendon sheath is a rare extrapulmonary presentation of tuberculosis that in itself is a common global health menace. Surgical debridement and histopathological examination forms the foundation of early diagnosis and treatment.

KEY WORDS: Extra Pulmonary Tuberculosis, Skeletal Tuberculosis, Tubercular Tenosynovitis, Ganglion, Rice Bodies.

Address for correspondence: Dr Kapil Rampal, F9/431, Street No 5, Gokal Avenue, P.O. Vijay Nagar, Amritsar, Punjab -143001, India. E-Mail: balkarankapil@gmail.com

\begin{tabular}{|c|c|c|}
\hline \multicolumn{3}{|c|}{ Online Access and Article Informtaion } \\
\hline $\begin{array}{c}\text { Quick Response code } \\
\text { Q }\end{array}$ & International Jour & $\begin{array}{l}\text { tegrative Medical Sciences } \\
\text { sciences.com }\end{array}$ \\
\hline Dol: 10.16965 ijims.2016.129 & $\begin{array}{l}\text { Received: 29-05-2016 } \\
\text { Reviewed: 29-05-2016 }\end{array}$ & $\begin{array}{l}\text { Accepted: 14-06-2016 } \\
\text { Published: 30-06-2016 }\end{array}$ \\
\hline
\end{tabular}

\section{INTRODUCTION}

Tuberculosis is a cosmopolitan health problem, that in its varied clinical manifestations continues to pose challenges before health workers. Spread of AIDS and growing drug resistance has added to the menace by rendering the available chemotherapy less effective. M usculoskeletal tuberculosis is a rare form of extra pulmonary tuberculosis even in developing countries accounting for less than $10 \%$ of the cases [1]. Articular tuberculosis remains most common amongst the musculoskeletal group. Tuberculosis of tendon sheath however is still a common underlying pathology in chronic tenosynovitis [2].

The clinical features are innocuous and hence presentation is usually delayed [3]. We present a case of tuberculosis of extensor tendon of wrist that presented to us as a ganglion.

\section{CASE REPORT}

22 year old male with no known co-morbidities presented to surgery department with history of a painless progressive swelling over right wrist for a duration of six months that had become painful on wrist movement for the last 03 days. There was no history of fever, trauma or similar swellings elsewhere in body. On examination patient had stable vitals and the systemic examination was within normal limits. On local examination, there was a $2.5 \mathrm{~cm} \times 2.5 \mathrm{~cm}$ non inflamed, non fluctuant, soft swelling over dorsum of right wrist that was mobile in a direction perpendicular to the underlying tendon [Figure 1].

Basic hematological and biochemical parameters were within normal limits. FNAC study aspirated gelatinous acellular aspirate and indicated the diagnosis of ganglion. Xray right hand was unremarkable.

Patient was taken up for surgical excision.

Intra op: gelatinious cyst originating from the extensor tendon sheath [Figure 2] and typical rice bodies [ Figure 3] that occupied space deeper to the gelatinous material. 
Necrotic tissue was debrided and wound closed primarily. Sutures removed after 08 days.

Histopathology: caseous necrosis with granuloma formation suggestive of tuberculosis [Figure 4].

Based on histopathology the patient was started on Cat I antitubercular treatment.

Fig. 1: Showing the non inflamed, non fluctuant, soft swelling over dorsum of right wrist.

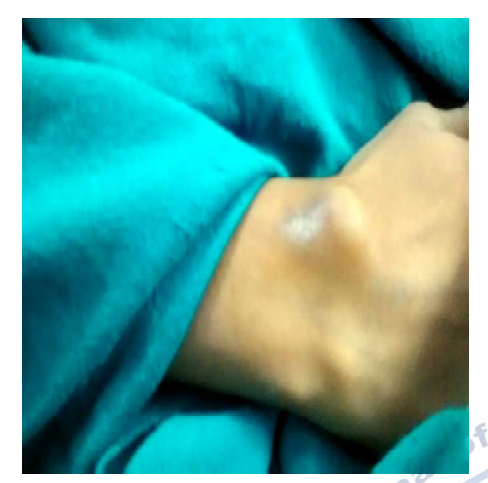

Fig. 2: Showing the gelatinious cyst originating from the extensor tendon sheath.
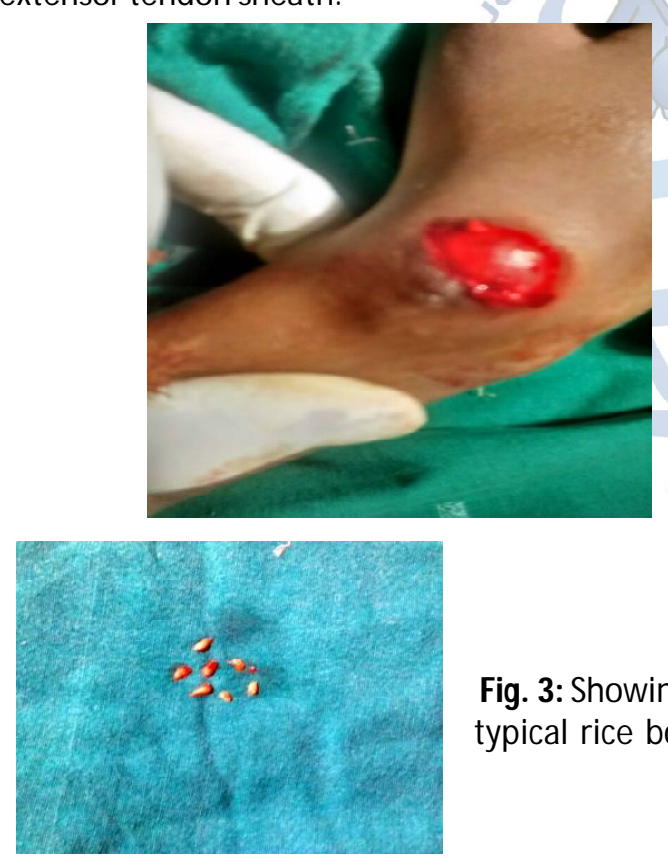

Fig. 3: Showing the typical rice bodies.

Fig. 4: Showing the caseous necrosis with granuloma formation.

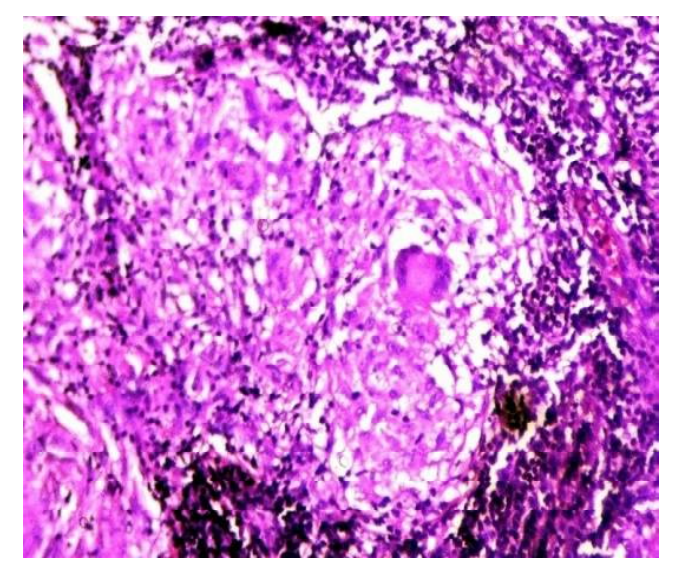

\section{DISCUSSION}

Primary tuberculosis tenosynovitis is a rare presentation of a common causative agent. TB tenosynovitis selectively targets the wrist and volar aspect of hand accounting for $5 \%$ cases of osteoarticular tuberculosis [4]. Incidence of disease in lower limb does not find much reference. In upper limb the flexor tendon sheath and radio-ulnar bursae( compound palmar ganglion) are common sites [5]. Digital flexor sheaths and the dorsal wrist compartment are not commonly affected [6-9]. Amine B et al have reported multifocal tenosynovitis in their study.

The source of infection can be local bone, muscle or joint infection or a hemo-lymphatic spread from a distant organ. The predisposing factors for disease manifestation are similar to as are for tuberculosis in general, namely extremes of age, immuno suppression, poor nutrition status, trauma, overuse wear and tear and low socioeconomic status. These factors thus cumulatively predispose right hand and wrist of a male to the disease. Like other tubercular afflictions the onset is insidious, progressing gradually with little signs or symptoms. Presentation may vary from local swelling, discharging sinus to a medical urgency in the form of carpal tunnel syndrome [6-9]. Delay and neglect can progress to tendon rupture [10]. Kanvel et al had reported 10 cases of tendon rupture amongst 21 patients they had studied [11]. The histology at presentation is variable subject to interplay of agent, host and environmental factors. In earliest form the tendon gets replaced by vascular granulation tissue. This is followed by obliteration of the sheath by fibrous tissue. Fluid collection is confined within the sheath. Typical rice bodies may appear at this stage. The tendon slowly gets destroyed by the inflammatory process and ruptures. Extensive caseation and granulation may produce sinus that predisposes the tendon to secondary infection [10-12]. Granulomas are characteristic but not definitive feature of tuberculosis. Rice bodies or melon seeds represent tubercles and are seen in about 50\% cases of tuberculosis [12-13]. Routine laboratory investigations are non specific and often non contributory. Bacteriological examination showing acid fast bacilli is confirmatory of TB. 
M RI scan, amongst all radiological investigations is the test of choice and shows synovial thickening, fluid collection within the tendon sheath and reactive thickening of the tendon. In contrast to acute suppurative infection, TB of tendon results in lesser fluid collection [13]. Pyogenic granuloma, sarcoidosis, rheumatoid arthiritis and foreign body granuloma form important differential diagnosis [14]. Development of fibrosismay result in partial persistence of tendon function even after the rupture of concerned tendon. Skofv et al described positive retroflexion sign comprising extension towards roof of bilateral thumbs while the palms rest flat over tableas a tool to assess rupture of extensor pollicis longus tendon [15]. Treatment protocols include both medical and surgical modalities complementing each other: Surgery includes curettage, lavage, synovectomy and debridement, Tendon itself is usually unhealthy and not amenable to primary repair. Anti tubercular chemotherapy is according to WHO (cat I/II) for 06 months that may have to be extended to $09-12$ months. $50 \%$ cases are known to recur [16]. A close follow up is thus warranted.

\section{CONCLUSION}

TB of tendon sheath is rare and the diagnosis is often delayed. Treatment involves both medical and surgical therapies complementing each other. Emphasis here is upon early diagnosis and use of histopathological examination as confirmatory modality.

\section{REFERENCES}

[1]. Lee SH, Abramson SB. Infections of the musculoskeletal system by $M$. tuberculosis. In Tuberculosis 4th edition. Edited by: Rom WN, Garay SM. New York, NY: Little, Brown and Company;1996;635-644.

[2]. Albornoz MA, M ezgarzedeh M, Neumann $\mathrm{CH}$, M yers AR. Granulomatous tenosynovitis: A rare musculoskeletal manifestation of tuberculosis. Clin Rheumatol 1998;17:166-169.

[3]. Jackson RH, King JW: Tenosynovitis of the hand: a forgotten manifestation of tuberculosis. Rev Infect Dis 1989;11:616-618.

[4]. Fnini S, Ouarab M, Rafai M, Cohen D, Largab A, Trafeh M. Anuncommon occupational accident: tuberculous tenosynovitis of the extensor of the hand. Chir Main 1999;18:309-312.
[5]. Hitesh Lall, Suman Kumar Nag, Vijay Kumar Jain, Rahul Khare and Deepak Mittal. Tuberculous extensor tenosynovitis of the wrist with extensor pollicis longus rupture: a case report. Journal of Medical Case Reports 2009;3:142.

[6]. Bickel WH, Kimbrough RF, Dahlin DC. Tuberculous tenosynovitis.J Am Med Assoc 1953;151(1):31-35.

[7]. Jaovisidha S, Chen C, Ryu KN, Siriwongpairat P, Pekanan P, Sartoris DJ, Resnick D. Tuberculous tenosynovitis and bursitis: imaging findings in 21 cases. Radiology 1996;201:507-513.

[8]. Pimm LH, Waugh W. Tuberculous tenosynovitis. J Bone Joint Surg Br 1957;39-B(1):91-101.

[9]. M ason ML. Tuberculous tenosyno vitis of the hand. A study of thirty-three cases of tuberculous tenosynovitis. Surg Gynecol Obstet 1934;59:363369.

[10]. Burkhardt E. Chronic diseases of the synovial sheath (from hand surgery consulting hour). Beitr Orthop Traumatol 1972;19:377-391.

[11]. Kanavel AB. Tuberculous tenosynovitis of the hand: a report of fourteen cases of tuberculous tenosynovitis. Surg Gynecol Obstet 1923;37:635647.

[12]. Aboudola S, Sienko A, Carey RB, Johnson S. Tuberculous tenosynovitis. Hum Pathol 2004;35(8):1044-1046.

[13]. Hoffman KA, Bergman AG, Hoffman DK, Harris DP. Tuberculosis tenosynovitis of the flexor tendons of the wrist: MR imaging with pathologic correlation. Skeletal Radiol 1996;25:186-188.

[14]. Hsu CY, Lu HC, Shih TT. Tuberculous infection of the wrist:MRI features. AJR Am J Roentgenol 2004;183(3):623-628.

[15]. Skoff HD. Postfracture extensor pollicis longus tenosyno vitis and tendon rupture: a scientific study and personal series.Am J Orthop 2003;32(5):245247.

[16]. Regnard PJ, Barry P, Isselin J. Mycobacterium tenosynovitis in the flexor tendons of the hands: $A$ report of five cases. J HandSurg [Br] 1996;21(3):351354.

How to cite this article: Kapil Rampal, Devendra K Prajapati, Meghna Sharma, Raj Kumar Indoliya. Tubercular Tenosynovitis of Extensor Tendon of Wrist Mimicking a Ganglion. Int J Intg Med Sci 2016; 3(6):318-320. DOI: 10.16965/ijims.2016.129 